\title{
The prognostic impact of concomitant coronary artery bypass grafting during aortic valve surgery: Implications for revascularization in the transcatheter era
}

Nassir M. Thalji, MBChB, ${ }^{\mathrm{a}}$ Rakesh M. Suri, MD, DPhil, ${ }^{\mathrm{a}}$ Richard C. Daly, MD, ${ }^{\mathrm{a}}$ Kevin L. Greason, MD, ${ }^{\mathrm{a}}$ Joseph A. Dearani, MD, ${ }^{a}$ John M. Stulak, MD, ${ }^{a}$ Lyle D. Joyce, MD, ${ }^{a}$ Harold M. Burkhart, MD, ${ }^{a}$ Alberto Pochettino, MD, ${ }^{\mathrm{a}}$ Zhuo Li, MSc, ${ }^{\mathrm{b}}$ Robert L. Frye, MD, ${ }^{\mathrm{c}}$ and Hartzell V. Schaff, $\mathrm{MD}^{\mathrm{a}}$

Objective: Clinicians may give greater consideration to medical management versus coronary artery bypass grafting (CABG) for coronary artery disease (CAD) at the time of aortic valve intervention. We evaluated the prognostic impact of revascularization strategy during aortic valve replacement (AVR).

Methods: We studied 1308 consecutive patients with significant CAD ( $\geq 50 \%$ stenosis) undergoing AVR with or with out CABG between 2001 and 2010. Late mortality and its determinants were analyzed using multivariable Cox models.

Results: Patients undergoing CABG $(\mathrm{n}=1043 ; 18 \%)$ had more frequent angina $(50 \%$ vs $26 \% ; P<.001)$, left ventricular dysfunction $(22 \%$ vs $14 \% ; P=.003)$, advanced $(>70 \%$ stenosis $)$ CAD $(85 \%$ vs $48 \% ; P<.001)$, and incidence of triple-vessel/left-main CAD $(44 \%$ vs $8 \% ; P<.001)$. Whereas operative mortality was comparable between patients undergoing AVR plus CABG versus isolated AVR $(2.9 \%$ vs $3.0 \% ; P=.90)$, 5 -year $(72 \%$ vs $64 \%)$ and 8 -year $(50 \%$ vs $39 \%)$ survival was higher following CABG $(P=.007)$. Adjusting for older age (hazard ratio [HR], 1.28 per 5 years), female sex (HR, 1.23), peripheral vascular disease (HR, 1.71), New York Heart Association functional class III to IV (HR, 1.48), and diabetes (HR, 1.50) concomitant CABG at AVR reduced late mortality risk by more than one-third (HR, 0.62, 95\% confidence interval, 0.49-0.79; $P<.001)$. CABG continued to confer a survival advantage in patients with moderate $(50 \%-70 \%)(\mathrm{HR}, 0.62$; $P=.02)$ and severe $(>70 \%)$ CAD (HR, $0.62 ; P=.002)$.

Conclusions: In patients undergoing AVR with coexistent CAD, concomitant CABG reduces risk of late death by more than one-third, without augmenting operative mortality. This survival advantage persists in moderate $(50 \%$ to $70 \%)$ and severe $(>70 \%)$ CAD. These findings underline the prognostic importance of revascularization in this population and should influence decisions regarding revascularization strategy in patients undergoing transcatheter valve therapy. (J Thorac Cardiovasc Surg 2015;149:451-60)

From the Division of Cardiovascular Surgery, ${ }^{\text {a }}$ Department of Biomedical Statistics and Informatics, ${ }^{b}$ and Division of Cardiovascular Diseases, ${ }^{c}$ Mayo Clinic, Rochester, Minn.

Supported by the Division of Cardiovascular Surgery of the Mayo Clinic.

Disclosures: The Division of Cardiovascular Surgery at the Mayo Clinic has research relationships with Edwards Life sciences, Medtronic, and St Jude Medical. Rakesh M. Suri is the national principal investigator for the Food and Drug Administration trial of the Sorin Perceval valve, a member of the steering committee of the St Jude Portico trial, a member of the clinical selection committee for the Abbott Coapt trial, and site principal investigator for the Edwards Partner II trial. Richard C. Daly serves on the advisory board of Neochord, Inc. None of the disclosures pertain to the current investigation. The other authors have nothing to disclose with regard to commercial support.

Read at the 94th Annual Meeting of The American Association for Thoracic Surgery, Toronto, Ontario, Canada, April 26-30, 2014.

Received for publication April 28, 2014; revisions received Aug 17, 2014; accepted for publication Aug 20, 2014.; available ahead of print Oct 11, 2014.

Address for reprints: Rakesh M. Suri, MD, DPhil, Division of Cardiovascular Surgery, Mayo Clinic College of Medicine; 200 First St, SW, Rochester, MN 55905 (E-mail: suri.rakesh@mayo.edu).

$0022-5223 / \$ 36.00$

Copyright $(2015$ by The American Association for Thoracic Surgery

http://dx.doi.org/10.1016/j.jtcvs.2014.08.073
See related commentary on pages 460-1.

Supplemental material is available online.

Coronary artery disease (CAD) is identified in almost half of patients undergoing aortic valve replacement (AVR), ${ }^{1,2}$ and-if left unmanaged-may negatively impact early and late postoperative outcomes. ${ }^{3,4}$ Previous iterations of the American Heart Association/American College of Cardiology (AHA/ACC) guidelines considered coronary artery bypass grafting (CABG) indicated (class I) for "significant" CAD ( $>70 \%$ stenosis $)$ at time of aortic valve replacement (AVR), and reasonable (class IIa) in patients with "moderate" CAD (50\%-70\% stenosis) 


$$
\begin{aligned}
& \text { Abbreviations and Acronyms } \\
& \text { ACC }=\text { American College of Cardiology } \\
& \text { AHA }=\text { American Heart Association } \\
& \text { AS }=\text { aortic stenosis } \\
& \text { AVR }=\text { aortic valve replacement } \\
& \text { CABG }=\text { coronary artery bypass grafting } \\
& \text { CAD }=\text { coronary artery disease } \\
& \text { LAD }=\text { left anterior descending } \\
& \text { LCX }=\text { left circumflex } \\
& \text { NYHA }=\text { New York Heart Association } \\
& \text { RCA }=\text { right coronary artery }
\end{aligned}
$$

(level of evidence: C). ${ }^{5}$ Recently updated recommendations have reclassified CABG at time of AVR for $>70 \%$ stenosis from a class I to a class IIa indication, whereas altogether deemphasizing the role of coronary revascularization in those with $50 \%$ to $70 \%$ stenosis. ${ }^{6}$ Recent randomized trials in patients with stable CAD have not demonstrated an advantage for revascularization over medical management in minimizing risk of myocardial infarction or death, except in patients with the most extensive (ie, triple-vessel) CAD. Considered alongside the revised guidelines for management of aortic valve disease, this may lead to the proposal that patients with less extensive and/or less severe CAD may be best served by conservative coronary management at $\mathrm{AVR}^{7,8}$

The optimal management of CAD at the time of valve intervention has been met with further uncertainty in light of the growing availability of minimally invasive and transcatheter platforms for AVR. Specifically, clinicians may give greater consideration to medical therapy versus $\mathrm{CABG}$ for the management of underlying $\mathrm{CAD}$ at aortic valve intervention. We therefore evaluated patients undergoing surgical AVR with or without CABG, all of whom had diagnoses of coexistent aortic stenosis (AS) and CAD at index surgery. We sought to determine the survival effect of the decision to perform concomitant $\mathrm{CABG}$ at the time of AVR, in contemporary practice and in patients with various distributions and severities of $\mathrm{CAD}$, testing the null hypothesis that the addition of CABG is prognostically neutral.

\section{METHODS \\ Study Subjects}

We evaluated all patients older than age 18 years who underwent surgical AVR for AS with or without concomitant CABG, between January 1, 2001, and December 31, 2010, and in whom there was evidence of significant $\mathrm{CAD}$ on preoperative coronary angiography. Exclusion criteria were prior sternotomy, active endocarditis, at least moderate aortic insufficiency, and concomitant major procedures other than CABG (ie, thoracic aortic surgery and mitral valve repair). A total of 1308 patients met enrollment criteria and were divided into 2 groups according to whether concomitant CABG was performed at the time of AVR
( $\mathrm{n}=1043$ CABG vs $\mathrm{n}=265$ no CABG). Enrollment was limited to patients operated on up to December 31,2010, to allow the opportunity for at least 3 years of follow-up in all patients, thus permitting us to more definitively comment upon the impact of concomitant CABG at AVR on long-term patient prognosis. The Mayo Clinic Institutional Review Board approved our study. Valid informed consent was obtained for all patients.

\section{Clinical Data}

Patient demographics, symptoms, medical/surgical history, cardiac status, and perioperative outcomes were derived from the Division of Cardiovascular Surgery database, and by review of medical records. Echocardiographic data was abstracted from the Division of Cardiovascular Diseases echocardiography database. Variable definitions were in accordance with criteria set forth by the Society of Thoracic Surgeons national database. Follow-up data were obtained from review of medical records, postal questionnaires, electronic Accurint database (www.Accurint.com), and death certificates. The primary end point was late all-cause mortality.

\section{Coronary Angiograms and Coronary Artery Disease}

Preoperative coronary angiograms within 6 months of surgery were available from the Division of Cardiovascular Disease Catheterization database and by review of medical records. CAD burden was evaluated according to percent luminal stenosis documented at the time of angiography. In keeping with ACC/AHA guidelines, significant $\mathrm{CAD}$ was defined as $\geq 50 \%$ luminal stenosis of any major epicardial coronary vessels, including side branches. ${ }^{5}$ In subset analyses, severe CAD was considered $>70 \%$ stenosis in at least 1 coronary vessel/branch, and moderate CAD defined as no more than $50 \%$ to $70 \%$ stenosis in any coronary vessel/branch. Proximal CAD was defined as $\geq 50 \%$ stenosis in the left main artery or the proximal one-third of the left anterior descending (LAD) artery, left circumflex (LCX) artery, or right coronary artery (RCA). All other coronary lesions were considered nonproximal disease.

\section{Statistical Analysis}

Continuous variables were summarized by means \pm standard deviation or medians and interquartile range and compared between groups using the Student $t$ test or Wilcoxon rank-sum test where appropriate. Categorical variables were summarized as counts and percentages and compared using the $\chi^{2}$ test or Fisher exact test where appropriate.

Long-term follow-up was calculated from time of surgery to death or last follow-up. Survival was estimated by Kaplan-Meier methods with patients censored at last known follow-up. The log-rank test compared overall survival between patients undergoing isolated AVR versus AVR with CABG. To examine the effect of performing CABG in managing various degrees and distributions of CAD at AVR, further survival curves were generated after stratifying patients into groups of moderate or severe $\mathrm{CAD}$; proximal or nonproximal CAD; single-vessel, double-vessel, or triple-vessel/left main $\mathrm{CAD}$; and among patients with single-vessel disease, LAD, LCX, or RCA disease.

Univariate and multivariate Cox proportional hazards models were used to identify predictors of late all-cause mortality in all patients. Parameters considered for selection were determined a priori and included age, female sex, New York Heart Association (NYHA) functional class III to IV, family history of CAD, smoking history, obesity (ie, body mass index $\geq 30$ ), history of cerebrovascular accident, diabetes, hypercholesterolemia, hypertension, prior myocardial infarction, peripheral vascular disease, previous percutaneous coronary intervention, ejection fraction $<50 \%$, aortic valve area, mean aortic valve gradient, percent coronary stenosis (ie, $50 \%$ to $70 \%$ or $>70 \%$ ), distribution of CAD (ie, single-vessel, double-vessel, or triple-vessel/left main $\mathrm{CAD}$ ), proximity of $\mathrm{CAD}$ (ie, proximal or nonproximal), surgical era (ie, 2001-2004, 2005-2007, or 2008-2010), surgical status (ie, elective or urgent/emergent), and 
performance of CABG at time of AVR. Variables were analyzed by multivariable methods if they were significant predictors of survival on univariate analysis, or if they were considered clinically relevant. Surgical coronary bypass was the primary independent variable of interest.

In secondary analysis, we generated multivariable Cox models with worsening aortic valve area and mean aortic valve gradient forced in as covariates. In further secondary analyses, and to minimize potential selection bias, we constructed a propensity score model to predict the probability of undergoing concomitant CABG at the time of AVR. ${ }^{9}$ Variables included in the propensity score model were age, female sex, NYHA functional class III to IV, diabetes, hypercholesterolemia, family history of CAD, prior myocardial infarction, peripheral vascular disease, ejection fraction $<50 \%$, angina, aortic valve area, mean aortic valve gradient, percent coronary stenosis (ie, $50 \%-70 \%$ or $>70 \%$ ), left main CAD, LAD artery disease, distribution of CAD (ie, single-vessel, double-vessel, or triplevessel disease), proximity of CAD (ie, proximal or nonproximal disease), surgical era, and surgical status. The receiver operating characteristic of the propensity score model was 0.84 . Using multivariable Cox proportional hazards methods, we analyzed the survival effect of CABG at time of AVR in all patients when adjusting for potential confounders, including propensity score, which was considered as a continuous variable.

In subgroup analyses, independent predictors of late mortality were determined for patients with severe CAD ( $>70 \%$ stenosis) and separately for those with moderate CAD (50\%-70\% stenosis) at the time of AVR. Further Cox models were constructed to examine the risk-adjusted survival effect of concomitant CABG at time of AVR after separately stratifying patients into those with proximal or nonproximal CAD; single-vessel, doublevessel and triple-vessel/left main CAD; and patients with single-vessel LAD artery disease. Of note, due to the small number of events (ie, late deaths) in patients with single-vessel LCX artery disease and singlevessel RCA, construction of predictive models with $>2$ variables in these patient subgroups would have resulted in overfitting and hence was inappropriate.

Finally, to more clearly understand the rationale behind the decision to forego coronary revascularization in patients with $>70 \%$ stenosis and/or triple-vessel/left main CAD undergoing isolated AVR, we reviewed historical patient records and categorized patients into 1 of 4 categories: diagonal/small/distal CAD, CAD deemed visually insignificant by surgeon, nongraftable $\mathrm{CAD}$, and prohibitive risk. Results were summarized as counts and percentages.

Analyses were performed using SAS 9.13 software (SAS Institute, Inc, Cary, NC).

\section{RESULTS}

\section{Baseline Clinical and Angiographic Characteristics}

Table 1 outlines baseline characteristics of all 1308 patients, stratified by whether CABG was performed at the time of AVR. Mean age was $75 \pm 9$ years and $31 \%$ (399) were women. Concomitant CABG at AVR was performed in $80 \%$ of patients (1043 out of 1308). Those undergoing a dual procedure were more likely to be men, had greater symptoms, and more baseline comorbidities. AS severity was modestly—although significantly—greater in patients undergoing isolated AVR.

All patients had preoperative angiographic evidence of significant CAD ( $\geq 50 \%$ stenosis). Median duration between angiography and surgery was 3 days (interquartile range, 1-11 days). Comparison of the burden, severity, and distribution of CAD between patients undergoing isolated AVR versus AVR with CABG is outlined in Table 1.
Patients undergoing concomitant CABG at time of AVR had a greater prevalence of severe $(>70 \%$ stenosis) and triple-vessel/left main CAD compared with those undergoing AVR only (all $P<.001$ ). Among patients with isolated AVR, nonproximal CAD was more prevalent than proximal disease. Patients were more likely to have surgical versus medical management of CAD at AVR, irrespective of which vessel was diseased, how many vessels were affected, and the severity of coronary obstruction. In patients with severe or triple-vessel/left main CAD undergoing AVR only, rationale for forgoing $\mathrm{CABG}$ was categorized into $\mathrm{CAD}$ limited to a diagonal artery, small vessel or distal vessel; CAD deemed visually insignificant by the surgeon; nongraftable coronary lesion; and/or prohibitive risk of concomitant CABG (Table E1).

\section{Perioperative Outcomes}

All patients underwent surgical AVR with CABG via a median sternotomy incision and using standard techniques for valve replacement and revascularization. Standard cardiopulmonary bypass and cold-blood cardioplegic arrest were used in all cases. Operative procedures and perioperative patient outcomes are outlined in Table 2. As expected, patients who underwent combined AVR and CABG had longer cardiopulmonary bypass and crossclamp times, postoperative mechanical ventilation and hospital length of stay (all $P$ values $<.001$ ). The addition of CABG at AVR had no effect on operative mortality rates (AVR with CABG, 2.9\% vs isolated AVR, $3.0 \% ; P=.90$ ).

\section{Long-Term Survival}

Mean follow-up was $4.7 \pm 3.1$ years, with a maximum of 12.5 years. Last year of follow-up was 2013. At follow-up completion, there were a total of 519 deaths $(40 \%)$ with a mean time to death of $4.2 \pm 3$ years.

Overall survival at $5(72 \%$ vs $64 \%)$ and $8(50 \%$ vs $39 \%)$ years was greater in patients undergoing surgical versus medical management of CAD at index $\operatorname{AVR}(P=.007)$ (Figure 1). Risk-unadjusted late survival was superior following AVR with CABG versus isolated AVR both in patients with moderate $\mathrm{CAD}(P=.02)$ (Figure $2, A)$ and severe $\operatorname{CAD}(P=.03)$ (Figure $2, B)$. In patients with proximal CAD (Figure 2, $C$ ) and those with nonproximal (Figure 2, D) CAD, risk-unadjusted long-term survival was again significantly higher with combined AVR plus CABG versus isolated AVR (proximal $P=.02$; nonproximal $P=.03$ ).

Probing late postoperative outcomes among subgroups of patients with various burdens of $\mathrm{CAD}$, we found that surgical coronary bypass at AVR was associated with improved survival in those with single-vessel disease $(P=.001)$ (Figure 3, A). Similar trends did not reach significance in patients with double-vessel $(P=.09)$ (Figure 3, $B$ ) and triple-vessel/left main $(P=.20)$ (Figure $3, C)$ CAD. Finally, 
TABLE 1. Baseline characteristics by surgical procedure

\begin{tabular}{|c|c|c|c|c|}
\hline Variable & Total $(\mathrm{N}=\mathbf{1 3 0 8})$ & $\operatorname{AVR}+\operatorname{CABG}(n=1043)$ & Isolated AVR $(n=265)$ & $P$ value* \\
\hline Age, y & $75 \pm 9$ & $75 \pm 9$ & $75 \pm 10$ & .91 \\
\hline Female sex & $399(31)$ & $302(29)$ & $97(37)$ & .02 \\
\hline NYHA class III-IV & $834(64)$ & $681(65)$ & $153(58)$ & .02 \\
\hline Angina & $590(45)$ & $521(50)$ & $69(26)$ & $<.001$ \\
\hline Congestive heart failure & $258(20)$ & 197 (19) & $61(23)$ & .14 \\
\hline Cerebrovascular accident & $80(6)$ & $68(7)$ & $12(5)$ & .21 \\
\hline Diabetes mellitus & $394(30)$ & $319(31)$ & $75(28)$ & .47 \\
\hline Hypercholesterolemia & $1092(83)$ & $895(86)$ & $197(74)$ & $<.001$ \\
\hline Family history of CAD & $151(12)$ & $132(13)$ & $19(7)$ & .009 \\
\hline Hypertension & $1024(78)$ & $820(79)$ & $204(77)$ & .57 \\
\hline Prior MI & $246(19)$ & $214(21)$ & $32(12)$ & .001 \\
\hline Obese (BMI $\geq 30)$ & $516(39)$ & $402(39)$ & $114(43)$ & .18 \\
\hline PVD & $181(14)$ & $150(14)$ & $31(12)$ & .25 \\
\hline Smoker & $801(61)$ & $644(62)$ & $157(59)$ & .46 \\
\hline Previous PCI & $228(17)$ & $178(17)$ & $50(19)$ & .49 \\
\hline Ejection fraction $<50 \%$ & $272(21)$ & $234(22)$ & $38(14)$ & .003 \\
\hline Charlson index & $3(1-5)$ & $3(1-5)$ & $2(1-5)$ & .08 \\
\hline Aortic valve area, $\mathrm{cm}^{2}$ & $0.87 \pm 0.25$ & $0.88 \pm 0.25$ & $0.84 \pm 0.22$ & .02 \\
\hline Mean gradient, $\mathrm{mm} \mathrm{Hg}$ & $48 \pm 15$ & $47 \pm 15$ & $52 \pm 13$ & $<.001$ \\
\hline Peak velocity, $\mathrm{m} / \mathrm{sec}$ & $4.4 \pm 0.7$ & $4.4 \pm 0.7$ & $4.6 \pm 0.6$ & $<.001$ \\
\hline Aortic valve area index, $\mathrm{cm}^{2} / \mathrm{m}^{2}$ & $0.45 \pm 0.12$ & $0.45 \pm 0.12$ & $0.43 \pm 0.11$ & .04 \\
\hline Percent coronary stenosis & & & & $<.001$ \\
\hline $50 \%-70 \%$ & $298(23)$ & $161(15)$ & $137(52)$ & \\
\hline$>70 \%$ & $1010(77)$ & $882(85)$ & $128(48)$ & \\
\hline LMA disease & $166(13)$ & $162(16)$ & $4(2)$ & $<.001$ \\
\hline LAD disease & $980(75)$ & $818(78)$ & $162(61)$ & $<.001$ \\
\hline LCX disease & $685(52)$ & $579(56)$ & $106(40)$ & $<.001$ \\
\hline RCA disease & $784(60)$ & $693(66)$ & $91(34)$ & $<.001$ \\
\hline CAD distribution & & & & $<.001$ \\
\hline 1 -vessel & 479 (37) & $293(28)$ & $186(70)$ & \\
\hline 2-vessel & $349(26)$ & $290(28)$ & $59(22)$ & \\
\hline 3-vessel/left-main & $480(37)$ & $460(44)$ & $20(8)$ & \\
\hline CAD location $\dagger$ & & & & $<.001$ \\
\hline Proximal & $816(62)$ & $738(71)$ & 78 (29) & \\
\hline Nonproximal & $492(38)$ & $305(29)$ & $187(71)$ & \\
\hline
\end{tabular}

Values are presented as mean \pm standard deviation, $\mathrm{n}(\%)$, or median (interquartile range). $A V R$, Aortic valve replacement; $C A B G$, coronary artery bypass grafting; $N Y H A$, New York Heart Association; $C A D$, coronary artery disease; $M I$, myocardial infarction; $B M I$, body mass index; $P V D$, peripheral vascular disease; $P C I$, percutaneous coronary intervention; $L M A$, left main artery; $L A D$, left anterior descending artery; $L C X$, left circumflex artery; $R C A$, right coronary artery. *Comparison of patients undergoing CABG plus AVR versus those undergoing isolated AVR. †Greater than $50 \%$ stenosis involving left-main, and/or proximal one-third of LAD, LCX, or RCA. All other patients considered to have nonproximal disease.

among patients with single-vessel CAD, concomitant $\mathrm{CABG}$ at AVR was associated with improved unadjusted late survival in those with LAD disease $(P=.001)$ (Figure 3, D), but not LCX disease $(P=.96)$ (Figure 3, $E)$ or RCA disease $(P=.21)$ (Figure $3, F)$.

In Cox proportional hazards analysis, concomitant CABG at AVR was a univariate predictor of reduced late mortality (hazard ratio [HR], $0.75 ; 95 \%$ confidence interval [CI], 0.61-0.93; $P=.009$ ). Using multivariable analysis, when adjusting for older age (HR, 1.28 per 5 years; $95 \%$ CI, 1.22-1.34; $P<.001$ ), female sex (HR, $1.23 ; 95 \%$ CI, 1.02-1.48; $P=.04$ ), peripheral vascular disease (HR, 1.71; 95\% CI, 1.35-2.14; $P<.001$ ), ejection fraction $<50 \%$ (HR, $1.53 ; 95 \%$ CI, 1.25-1.86; $P<.001$ ), diabetes mellitus (HR, 1.50; 95\% CI, 1.24-1.79; $P<.001$ ), and NYHA functional class III to IV (HR, $1.48 ; 95 \% \mathrm{CI}$, $1.20-1.83 ; P<.001)$, the addition of concomitant CABG at the time of AVR was associated with a greater than one-third reduction in the risk of late mortality (HR, 0.62; 95\% CI, 0.49-0.79; $P<.001$ ) (Table 3).

In subgroup analyses, again controlling for potential confounders, the addition of CABG at valve surgery independently predicted favorable late prognosis in those with moderate (adjusted HR, 0.62; 95\% CI, 0.41-0.93; $P=.02$ ) as well as severe (adjusted HR, 0.62; 95\% CI, 0.46-0.84; $P=.002$ ) CAD (Table 3). Coronary revascularization persisted as an independent predictor of improved survival in patients with proximal CAD $(P=.004)$ and/or 
TABLE 2. Operative details and postoperative outcomes by surgical procedure

\begin{tabular}{|c|c|c|c|c|}
\hline Variable & Total $(\mathbf{N}=\mathbf{1 3 0 8})$ & AVR plus CABG $(n=1043)$ & Isolated AVR $(n=265)$ & $P$ value* \\
\hline Surgical era & & & & .13 \\
\hline 2001-2004 & $502(39)$ & $412(40)$ & $90(34)$ & \\
\hline $2005-2007$ & $381(29)$ & $305(29)$ & $76(27)$ & \\
\hline $2008-2010$ & $425(32)$ & $326(31)$ & $99(39)$ & \\
\hline Surgical status & & & & .001 \\
\hline Elective & $1081(83)$ & $843(81)$ & $239(90)$ & \\
\hline Urgent/emergent & 227 (17) & $200(19)$ & $27(10)$ & \\
\hline Cardiopulmonary bypass time, min & $96 \pm 38$ & $104 \pm 36$ & $63 \pm 25$ & $<.001$ \\
\hline Crossclamp time, $\min$ & $72 \pm 28$ & $79 \pm 27$ & $47 \pm 17$ & $<.001$ \\
\hline Prosthesis type & & & & .40 \\
\hline Mechanical & $186(14)$ & $148(14)$ & $38(14)$ & \\
\hline Bioprosthetic & $1122(86)$ & $895(86)$ & $227(86)$ & \\
\hline Atrial fibrillation & $516(39)$ & $411(39)$ & $105(40)$ & .95 \\
\hline Perioperative myocardial infarction & $6(0.5)$ & $4(0.4)$ & $2(0.8)$ & .45 \\
\hline Stroke & $15(1.1)$ & $12(1.2)$ & $3(1.1)$ & .45 \\
\hline Mechanical ventilation, $\mathrm{h}$ & $12(7-17)$ & $13(8-18)$ & $9(6-16)$ & $<.001$ \\
\hline Intensive care unit stay, $h$ & $26(22-49)$ & $27(22-58)$ & $25(22-45)$ & .13 \\
\hline Operative mortality & $38(2.9)$ & $30(2.9)$ & $8(3)$ & .90 \\
\hline Hospital length of stay, $d$ & $7(5-9)$ & $7(5-9)$ & $6(5-8)$ & $<.001$ \\
\hline
\end{tabular}

nonproximal $(P=.009) \mathrm{CAD}$ (Table E2), those with singlevessel CAD $(P=.004)$ (Table E3), and particularly in patients with single-vessel LAD $(P<.001)$ (Table E4). The risk-adjusted survival effect of concomitant CABG did not reach significance in patients with double-vessel $(P=.058)$, or triple-vessel/left main $\mathrm{CAD}(P=.36)$ (Table E3).

In a secondary analysis of all patients, when adjusting for baseline AS severity in a multivariable Cox model, worsening aortic valve area (HR, 1.02 per $0.1 \mathrm{~cm}^{2}$ decrease;

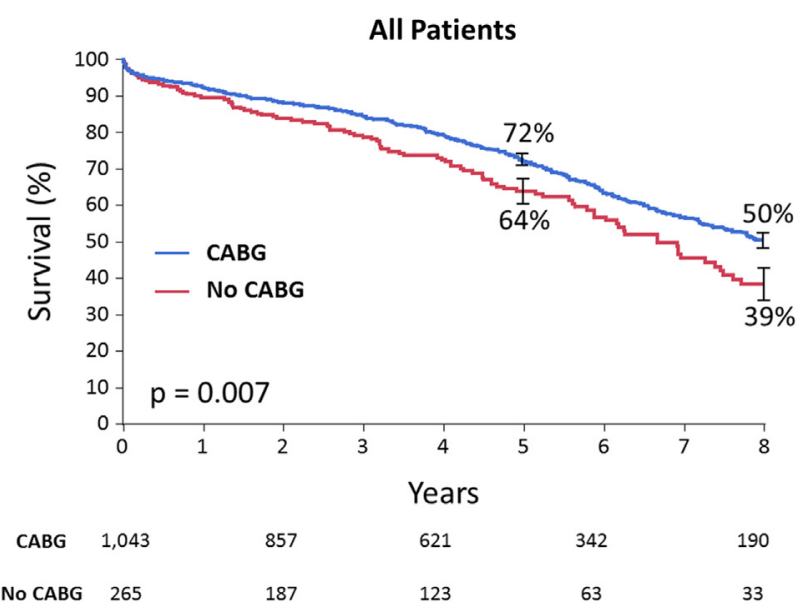

FIGURE 1. Overall long-term survival estimates after isolated aortic valve replacement versus combined aortic valve replacement plus coronary artery bypass graft $(C A B G)$ surgery. Five- and 8-year survival rates for patients with coexistent aortic valve and coronary artery disease undergoing aortic valve replacement with or without concomitant CABG. Vertical bars are $68 \%$ confidence intervals representing \pm 1 standard error.
95\% CI, 0.99-1.07; $P=.23$ ) and mean gradient (HR, 1.0 per $10 \mathrm{~mm} \mathrm{Hg}$ increase; 95\% CI, 0.94-1.06; $P=.95$ ) were not predictive of late mortality risk, whereas concomitant CABG remained an independent determinant of improved long-term survival $(P<.001)$.

To minimize potential selection bias we developed a propensity score model to calculate the probability of undergoing $\mathrm{CABG}$ at AVR. The median propensity score for patients undergoing concomitant CABG was 0.423 (interquartile range, 0.229-0.593) compared with 0.091 (interquartile range, $0.029-0.224)$ in those without coronary bypass at valve surgery $(P<.001)$. When adjusting for the confounding effects of older age, female sex, peripheral vascular disease, diabetes, NYHA functional class III to IV, ejection fraction $<50 \%$, mean aortic valve gradient, and propensity score, concomitant CABG at the time of AVR remained an independent determinant of long-term survival (HR, $0.65 ; 95 \% \mathrm{CI}, 0.51-0.84 ; P<.001)$ in all patients.

\section{DISCUSSION}

Although CABG has previously been recommended at AVR in patients with underlying coronary stenosis, ${ }^{5}$ contemporary lines of evidence have raised into question prognostic utility of coronary bypass in various patient subsets. In line with randomized trials that have demonstrated no advantage of revascularization over medical therapy in patients with nonextensive (ie, non triplevessel) $\mathrm{CAD},{ }^{7,8}$ recently revised $\mathrm{AHA} / \mathrm{ACC}$ guidelines have downplayed the role of coronary intervention at AVR. ${ }^{6}$ Further, in the era of transcatheter AVR, the 

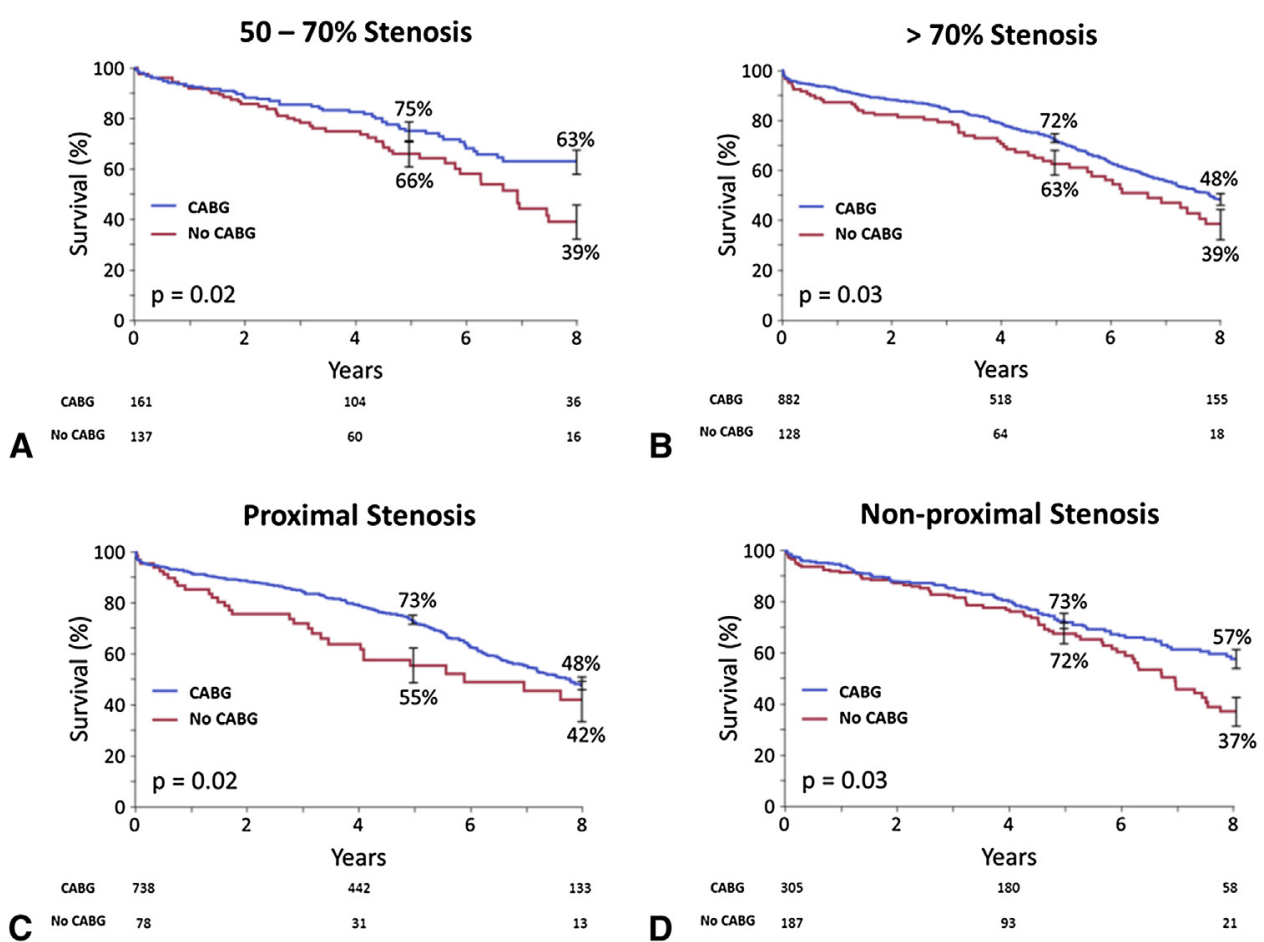

FIGURE 2. Long-term survival estimates after isolated aortic valve replacement versus combined aortic valve replacement plus coronary artery bypass graft $(C A B G)$ surgery by coronary artery disease severity and location. Vertical bars are $68 \%$ confidence intervals representing \pm 1 standard error. A, $50 \%$ to $70 \%$ stenosis. B, $>70 \%$ stenosis. C, Proximal stenosis. D, Nonproximal stenosis.

optimal management of coexistent CAD at valve intervention remains understudied. We hence sought to determine the incremental value of CABG over medical management of CAD in patients presenting to conventional AVR. Our study clearly shows that CABG can be safely performed at the time of valve replacement without compromising operative mortality. Further, we demonstrate that addition of CABG when technically feasible at AVR independently reduces late mortality risk by more than one-third, and that this survival benefit persists in patients with moderate $(50 \%-70 \%)$ and severe $(>70 \%$ stenosis) CAD. Although supporting attitudes that advocate coronary bypass at the time of conventional AVR, ${ }^{5}$ these findings may further impact future decisions regarding the management of coexistent $\mathrm{CAD}$ in patients undergoing minimally invasive AVR or transcatheter valve implantation/replacement.

In line with prior reports, ${ }^{1}$ our group recently documented that approximately one-half of patients coming to conventional AVR have angiographic evidence of significant CAD. ${ }^{2}$ The prognostic impact of unrevascularized coronary stenosis following valve surgery is critical in determining the relative merits of performing CABG at index AVR. Although Bonow and colleagues ${ }^{10}$ documented comparable short- and long-term outcomes following surgical AVR in patients with AS versus AS plus $\mathrm{CAD}$, it is noteworthy that their evaluation was limited to only 55 patients with $\mathrm{CAD}$, almost half of whom had single-vessel disease. Conversely, in an assessment of a larger patient cohort, Mullany and colleagues $^{4}$ detailed significantly inferior 10 -year survival rates following AVR in patients with AS plus CAD versus AS only $(36 \%$ vs $63 \% ; P<.01)$. Similarly, and in separate analyses, Lund, Czer, and colleagues ${ }^{3,11}$ reported that untreated coexistent CAD was an independent determinant of poor outcome following AVR. In light of the deleterious effects of unmanaged CAD on postoperative outcome, our finding that addition of CABG at AVR is associated with improved long-term survival is logical. To be precise, surgical revascularization may serve to neutralize the baseline risk inherent to untreated CAD.

Reservations surrounding the performance of CABG at AVR have concerned the perceived increased early mortality risk following a combined procedure versus AVR only. Over the past decade the Society of Thoracic Surgeons National Cardiac Database has reported a modest, although persistently higher operative mortality rate in patients undergoing AVR with CABG (4.5\%) versus isolated AVR $(3 \%){ }^{12}$ This finding is echoed by various studies demonstrating an association between concomitant CABG and differing short-term outcomes. ${ }^{13-16}$ However, these survival estimates were derived by comparing patients with isolated AS undergoing AVR only versus those with 
All Patients

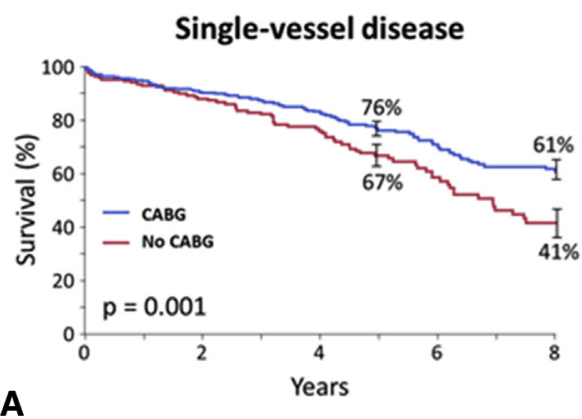

A

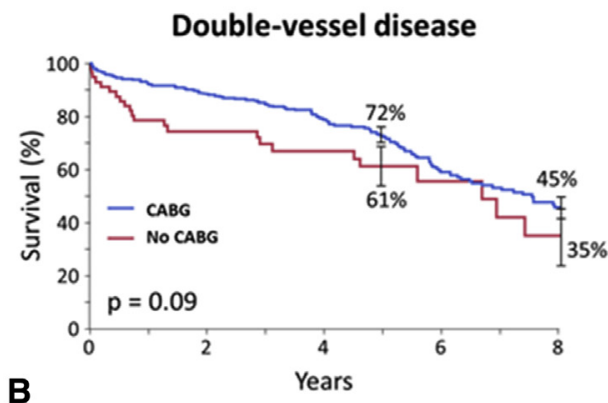

B

3-vessel/LMA

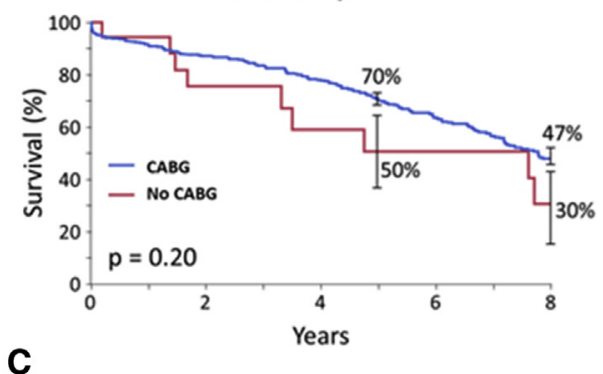

Single-vessel CAD

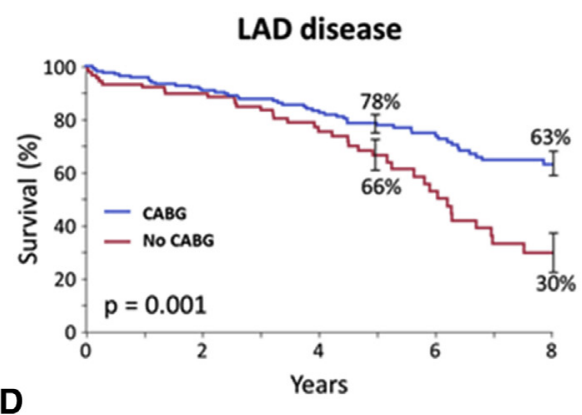

LCX disease
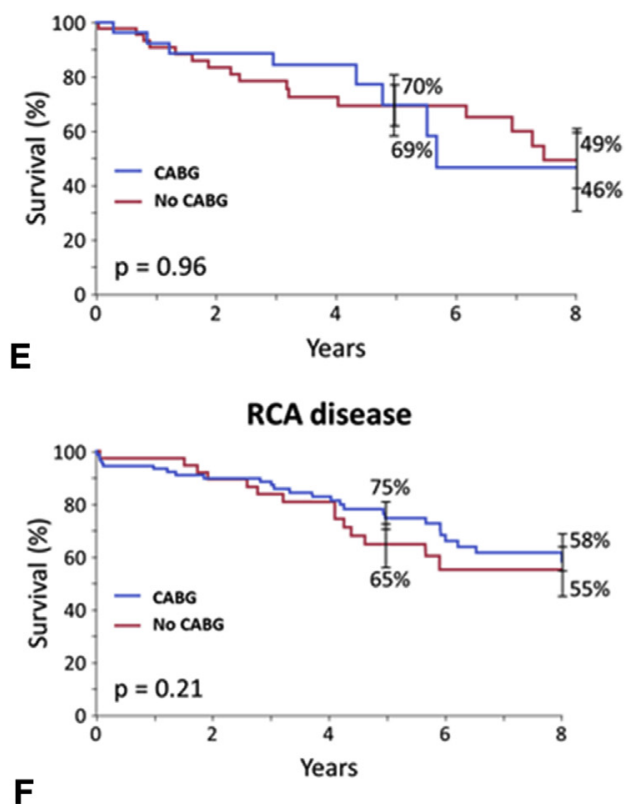

FIGURE 3. Long-term survival estimates after isolated aortic valve replacement versus combined aortic valve replacement plus coronary artery bypass graft $(C A B G)$ surgery by coronary artery disease distribution. Vertical bars are $68 \%$ confidence intervals representing \pm 1 standard error. A, Single vessel disease. B, Double-vessel disease. C, Triple-vessel disease/left circumflex disease. D, Left anterior descending disease. E, Left circumflex disease. F, Right coronary artery disease. $C A D$, Coronary artery disease; $L A D$, left anterior descending; $L C X$, left circumflex; $R C A$, right coronary artery; $L M A$, left main artery.

coexistent AS and CAD undergoing AVR with CABG. A detailed analysis by Beach and colleagues ${ }^{17}$ recently highlighted that early postoperative risks incurred by patients with AS plus CAD (having AVR with CABG) are largely a function of baseline $\mathrm{CAD}$, rather than $\mathrm{CABG}$ per se. Thus, by solely studying patients with both AS and CAD undergoing AVR with or without CABG, our unique contemporary study design allows for investigation of postoperative risk inherent to the performance of concomitant CABG. Indeed, our results coincide with historical reports $^{4,11}$ as we demonstrate that among patients with $\mathrm{CAD}$, early operative mortality rates are not augmented by the addition of CABG at AVR. This is also in keeping with more recent data attesting to the safety of coronary revascularization at AVR even in high-risk elderly patients. $^{18,19}$
Our findings also clearly demonstrate superior 5- and 8-year survival rates in patients with CABG versus medical management for coexistent CAD at index AVR. After adjusting for the confounding effects of older age, female sex, peripheral vascular disease, reduced ejection fraction, diabetes mellitus, and NYHA class III to IV, CABG was independently associated with a more than one-third reduction in the risk of late all-cause mortality. Of note, this trend differs from data presented in studies by Kvidal, de Waard, and colleagues ${ }^{20,21}$ that reported reduced late survival following addition of CABG at the time of AVR. However, on covariate adjustment this negative relationship was lost in both studies, and was hence likely attributable to the increased risk profile in patients undergoing additional CABG. Further, results of studies carried out by Kurlansky and colleagues, ${ }^{22}$ Vicchio and 
TABLE 3. Multivariable predictors of late all-cause mortality: Overall and by coronary artery disease severity

\begin{tabular}{|c|c|c|c|c|c|c|}
\hline \multirow[b]{2}{*}{ Variable } & \multicolumn{2}{|c|}{ All patients $(N=1308)$} & \multicolumn{2}{|c|}{$50 \%$ to $70 \%$ Stenosis $*(n=298)$} & \multicolumn{2}{|c|}{$>70 \%$ Stenosis $\dagger(n=1010)$} \\
\hline & HR $(95 \%$ CI $)$ & $P$ value & HR $(95 \%$ CI $)$ & $P$ value & HR $(95 \%$ CI $)$ & $P$ value \\
\hline Peripheral vascular disease & $1.71(1.35-2.14)$ & $<.001$ & $1.51(0.87-2.50)$ & .14 & $1.76(1.35-2.26)$ & $<.001$ \\
\hline Ejection fraction $<50 \%$ & $1.53(1.25-1.86)$ & $<.001$ & $1.22(0.73-1.97)$ & .43 & $1.64(1.31-2.03)$ & $<.001$ \\
\hline Diabetes mellitus & $1.50(1.24-1.79)$ & $<.001$ & $1.95(1.25-2.98)$ & .004 & $1.43(1.16-1.75)$ & $<.001$ \\
\hline NYHA functional class III-IV & $1.48(1.20-1.83)$ & $<.001$ & $1.81(1.15-2.89)$ & .009 & $1.38(1.09-1.76)$ & .008 \\
\hline Age $\ddagger$ & $1.28(1.22-1.34)$ & $<.001$ & $1.22(1.05-1.40)$ & .001 & $1.28(1.22-1.34)$ & $<.001$ \\
\hline Female sex & $1.23(1.02-1.48)$ & .04 & $0.75(0.47-1.16)$ & .19 & $1.37(1.11-1.68)$ & .004 \\
\hline Coronary artery bypass grafting & $0.62(049-0.79)$ & $<.001$ & $0.62(0.41-0.93)$ & .02 & $0.62(0.46-.84)$ & .002 \\
\hline
\end{tabular}

$H R$, Hazard ratio; $C I$, confidence interval; NYHA, New York Heart Association. *Subgroup analysis in patients with no more than $50 \%$ to $70 \%$ luminal stenosis in any coronary vessel or branch. $†$ Subgroup analysis in patients with a maximal luminal stenosis $>70 \%$ in at least 1 coronary vessel or branch. $\ddagger$ Age increase by 5 -year increments.

colleagues, ${ }^{16}$ as well as a recent meta-analysis by Tjang and colleagues ${ }^{23}$ examining predictors of mortality following aortic valve surgery, found that there was little evidence to support concomitant $\mathrm{CABG}$ as a risk factor for mortality following AVR. Again, a common limitation shared by these studies is their comparison of patients with isolated AS coming to AVR versus patients with AS plus CAD undergoing combined AVR and CABG. When taken in line with our data, it may be proposed that by evaluating cohorts that were heterogeneous with regard to the presence/absence of baseline $\mathrm{CAD}$, the true prognostic benefit of concomitant CABG may have been masked in these studies.

When subdividing patients on the basis of CAD severity, we further demonstrate that $\mathrm{CABG}$ at AVR confers a late survival benefit for all categories of significant CAD. Specifically, addition of coronary bypass at index surgery reduced the hazard of late death in patients with moderate $(50 \%-70 \%)$ and severe $(>70 \%)$ coronary stenosis by more than one-third. Although in keeping with current guidance recommending CABG at AVR in patients with severe $\mathrm{CAD},{ }^{6}$ it further supports the prognostic utility of CABG in patients with moderate $\mathrm{CAD}$, in whom the need for concomitant revascularization has been deemphasized between previous ${ }^{5}$ and newly revised iterations ${ }^{6}$ of AHA/ ACC guidelines. We observed similar patterns of increased survival following CABG in patients with proximal as well as nonproximal $\mathrm{CAD}$, again highlighting the late prognostic value conferred by concomitant $\mathrm{CABG}$ in all distributions of CAD when surgically feasible. Although our analyses also revealed long-term benefit associated with the CABG at AVR in those with single-vessel disease, comparable trends in those with double-vessel and triple-vessel/left-main coronary disease did not reach statistical significance. Considering that only 59 patients with double-vessel and 20 with triple-vessel/left-main CAD underwent isolated AVR in our population, it is likely that our study was underpowered to detect significant survival differences between AVR and AVR plus CABG in these subgroups. Meanwhile, a more detailed evaluation of patients with single-vessel disease suggests that the late survival benefit of CABG at AVR is largely driven by revascularization of the $\mathrm{LAD}$, which on average perfuses approximately half of the left ventricular myocardial mass, and when diseased is associated with a relatively poor prognosis. ${ }^{24-26}$ Collectively, and in the context of patients undergoing AVR, we present compelling evidence attesting to late prognostic benefits of concomitant surgical revascularization for management of various permutations of CAD.

It may be proposed that late outcome is more favorable in our cohort of patients undergoing AVR plus CABG versus isolated AVR due to less severe AS. This is however doubtful considering that when adjusting for markers of AS severity in multivariable models, not only were worsening aortic valve area $(P=.21)$ and mean gradient $(P=.85)$ not predictive of poor late outcome, but CABG remained an independent determinant of improved longterm survival $(P<.001)$. It is likely that AS severity does not influence long-term outcomes in this population given that all patients underwent baseline AVR, thus neutralizing any prognostic risk that may potentially be imposed by AS. In response to the argument that greater AS may be a marker of an advanced cardiac risk profile- and thus AVR may not entirely eliminate late mortality risk-we note that baseline cardiac risk profiles were comparable if not more favorable in patients undergoing AVR only versus combined AVR plus CABG; again supporting the argument that the late survival benefit observed in patients with AVR plus CABG is a byproduct of baseline coronary revascularization.

Meanwhile, in patients presenting for minimally invasive AVR or transcatheter AVR, underlying CAD is identified in anywhere from $40 \%$ to $75 \%$ of patients, yet the optimal strategy for its management remains understudied and therefore unclear. ${ }^{27}$ Evaluating 201 patients undergoing transcatheter AVR, Dewey and colleagues ${ }^{28}$ reported that a history of CAD was associated with a 10-fold increase in 30-day mortality risk, and more than doubled the risk of death at any point in time. Yet, studying 191 patients coming to transcatheter AVR, $60 \%$ of whom had coexistent CAD, Gasparetto and colleagues ${ }^{29}$ detailed that 
30-day and 12-month survival rates were no different between those who underwent revascularization versus conservative management of CAD. Hence, whereas safety and feasibility of percutaneous coronary intervention, either concomitantly or staged at the time of valve intervention, have been established, ${ }^{30,31}$ whether noncritical CAD warrants revascularization in these patients remains uncertain. Importantly, our investigation does not propose to determine the safety and efficacy of surgical AVR plus CABG versus transthoracic AVR plus percutaneous coronary intervention. Randomized trials evaluating this important clinical question are underway, and results will be forthcoming. Instead, our study provides clinicians managing patients with coexistent $\mathrm{CAD}$ at aortic valve intervention with valuable insights as to the safety and prognostic value of concomitant coronary revascularization at the time of index aortic valve therapy.

\section{Limitations}

Given the observational nature of our study, it is not possible to completely rule out the possibility of selection bias in the allocation of patients to undergo or forego concomitant CABG at the time of AVR. Nevertheless, in an effort to control for such bias we constructed a propensity score model and adjusted for the propensity score as a covariate in multivariable analysis. A final limitation is the retrospective nature of our investigation. Although the guidelines suggest that $\mathrm{CABG}$ is indicated in patients with severe $(>70 \%)$ CAD undergoing $\mathrm{AVR}^{6}$ - and whereas in general we abide by the guidelines in our surgical practice - on review of historical patient records it was at times unclear as to why CABG was not performed in a subset of these patients. However, it was evident in a subset of patients that coronary revascularization was technically inappropriate, suggesting that the apparent prognostic benefit of CABG may not be attainable in all patients. In circumstances whereby concomitant $\mathrm{CABG}$ cannot be safely/effectively performed at the time of AVR, these patients may require extra vigilance in follow-up and medical management of CAD. A prospective randomized trial of AVR plus CABG versus isolated AVR in the presence of coexistent CAD, while necessary, remains outstanding. In the interim, our study provides robust evidence as to the merits of concomitant $\mathrm{CABG}$ - when technically feasible - at the time of AVR for the management of underlying significant CAD.

\section{CONCLUSIONS}

In patients coming to surgical AVR with underlying $>50 \%$ CAD, concomitant CABG when technically feasible independently reduces the risk of late mortality by more than one-third without compromising early postoperative outcomes. The late survival benefit conferred by CABG influences both patients with moderate $(50 \%-70 \%)$ and severe $(>70 \%)$ CAD. These data highlight the prognostic importance of concomitant coronary revascularization at the time of aortic valve intervention, and may have implications in therapeutic planning in the era of minimally invasive and transcatheter aortic valve therapy.

\section{References}

1. Exadactylos N, Sugrue DD, Oakley CM. Prevalence of coronary artery disease in patients with isolated aortic valve stenosis. Br Heart J. 1984;51:121-4.

2. Thalji NM, Suri RM, Daly RC, Dearani JA, Burkhart HM, Park SJ, et al. Assessment of coronary artery disease risk in 5463 patients undergoing cardiac surgery: when is preoperative coronary angiography necessary? J Thorac Cardiovasc Surg. 2013;146:1055-63.

3. Lund O, Nielsen T, Pilegaard H, Magnussen K, Knudsen M. The influence of coronary artery disease and bypass grafting on early and late survival after valve replacement for aortic stenosis. J Thorac Cardiovasc Surg. 1990;100:327-37.

4. Mullany CJ, Elveback LR, Frye RL, Pluth JR, Edwards WD, Orszulak TA, et al. Coronary artery disease and its management: influence on survival in patients undergoing aortic valve replacement. J Am Coll Cardiol. 1987;10:66-72.

5. Bonow RO, Carabello B, Chatterjee K, de Leon AC, Faxon DP, Freed MD, et al. ACC/AHA 2006 Guidelines for the Management of Patients With Valvular Heart Disease: a report of the American College of Cardiology/American Heart Association Task Force on Practice Guidelines. J Am Coll Cardiol. 2006;48:e1-148.

6. Nishimura RA, Otto CM, Bonow RO, Carabello BA, Erwin JP, Guyton RA, et al. 2014 AHA/ACC Guideline for the Management of Patients with Valvular Heart Disease. J Am Coll Cardiol. 2014;63:1-234.

7. Frye RL, August P, Brooks MM, Hardison RM, Kelsey SF, MacGregor JM, et al. A randomized trial of therapies for type 2 diabetes and coronary artery disease. $N$ Engl J Med. 2009;360:2503-15.

8. Boden WE, O'Rourke RA, Teo KK, Hartigan PM, Maron DJ, Kostuk WJ, et al. Optimal medical therapy with or without PCI for stable coronary disease. $N$ Engl J Med. 2007;356:1503-16.

9. Austin PC. An introduction to propensity score methods for reducing the effects of confounding in observational studies. Multivariate Behav Res. 2011;46:399-424.

10. Bonow RO, Kent KM, Rosing DR, Lipson LC, Borer JS, McIntosh CL, et al Aortic valve replacement without myocardial revascularization in patients with combined aortic valvular and coronary artery disease. Circulation. 1981;63: 243-51.

11. Czer L, Gray R, Stewart M, De Robertis M, Chaux A, Matloff J. Reduction in sudden late death by concomitant revascularization with aortic valve replacement. J Thorac Cardiovasc Surg. 1988;95:390-401.

12. Society of Thoracic Surgeons Adult Cardiac Surgery Database Executive Summary. Available at: http://www.sts.org/sts-national-database/database-mana gers/executive-summaries. Accessed March 24, 2014.

13. Berndt TB, Hancock EW, Shumway NE, Harrison DC. Aortic valve replacemen with and without coronary artery bypass surgery. Circulation. 1974;50:967-71.

14. Kuduvalli M, Grayson AD, Au J, Grotte G, Bridgewater B, Fabri BM. A multicentre additive and logistic risk model for in-hospital mortality following aortic valve replacement. Eur J Cardiothorac Surg. 2007;31:607-13.

15. Edwards FH, Peterson ED, Coombs LP, DeLong ER, Jamieson WR Shroyer ALW, et al. Prediction of operative mortality after valve replacement surgery. J Am Coll Cardiol. 2001;37:885-92.

16. Vicchio M, Feo MD, Giordano S, Provenzano R, Cotrufo M, Nappi G. Coronary artery bypass grafting associated to aortic valve replacement in the elderly: survival and quality of life. J Cardiothorac Surg. 2012;7:1-6.

17. Beach JM, Mihaljevic T, Svensson LG, Rajeswaran J, Marwick T, Griffin B, et al. Coronary artery disease and outcomes of aortic valve replacement for severe aortic stenosis. J Am Coll Cardiol. 2013;61:837-48.

18. Abel NJ, Rogal GJ, Burns P, Saunders CR, Chamberlain RS. Aortic valve replacement with and without coronary artery bypass graft surgery in octogenarians: is it safe and feasible? Cardiology. 2013;124:163-73.

19. Dell'Amore A, Aquino TM, Pagliaro M, Lamarra M, Zussa C. Aortic valve replacement with and without combined coronary bypass grafts in very elderly patients: early and long-term results. Eur J Cardiothorac Surg. 2012;41:491-8.

20. Kvidal P, Bergström R, Hörte LG, Ståhle E. Observed and relative survival after aortic valve replacement. J Am Coll Cardiol. 2000;35:747-56. 
21. De Waard G, Jansen EK, de Mulder M, Vonk AB, Umans VA. Long-term outcomes of isolated aortic valve replacement and concomitant AVR and coronary artery bypass grafting. Neth Heart J. 2012;20:110-7.

22. Kurlansky PA, Williams DB, Traad EA, Carrillo RG, Zucker M, Ebra G. Surgical management of aortic valve disease in elderly patients with and without coronary artery disease: influence on quality of life. J Cardiovasc Surg (Torino). 2007:48:215-26.

23. Tjang YS, van Hees Y, Körfer R, Grobbee DE, van der Heijden GJ. Predictors of mortality after aortic valve replacement. Eur J Cardiothorac Surg. 2007;32: 469-74.

24. Jones RH, Kesler K, Phillips HR, Mark DB, Smith PK, Nelson CL, et al. Long-term survival benefits of coronary artery bypass grafting and percutaneous transluminal angioplasty in patients with coronary artery disease. J Thorac Cardiovasc Surg. 1996;111:1013-25.

25. Hannan EL, Racz MJ, McCallister BD, Ryan TJ, Arani DT, Isom OW, et al. A comparison of three-year survival after coronary artery bypass graft surgery and percutaneous transluminal coronary angioplasty. J Am Coll Cardiol. 1999;33:63-72.

26. Mahmarian JJ, Pratt CM, Boyce TM, Verani MS. The variable extent of jeopardized myocardium in patients with single vessel coronary artery disease: Quantification by thallium-201 single photon emission computed tomography. J Am Coll Cardiol. 1991;17:355-62.
27. Goel SS, Ige M, Tuzcu EM, Ellis SG, Stewart WJ, Svensson LG, et al. Severe aortic stenosis and coronary artery disease-implications for management in the transcatheter aortic valve replacement era: a comprehensive review. J Am Coll Cardiol. 2013;62:1-10.

28. Dewey TM, Brown DL, Herbert MA, Culica D, Smith CR, Leon MB, et al. Effect of concomitant coronary artery disease on procedural and late outcomes of transcatheter aortic valve implantation. Ann Thorac Surg. 2010; 89:758-67.

29. Gasparetto V, Fraccaro C, Tarantini G, Buja P, D'Onofrio A, Yzeiraj E, et al. Safety and effectiveness of a selective strategy for coronary artery revascularization before transcatheter aortic valve implantation. Catheter Cardiovasc Interv. 2013;81:376-83.

30. Wenaweser P, Pilgrim T, Guerios E, Stortecky S, Huber C, Khattab AA, et al. Impact of coronary artery disease and percutaneous coronary intervention on outcomes in patients with severe aortic stenosis undergoing transcatheter aortic valve implantation. EuroIntervention. 2011;7:541-8.

31. Kodali SK, Moses JW. Coronary artery disease and aortic stenosis in the transcatheter aortic valve replacement era: old questions, new paradigms: the evolving role of percutaneous coronary intervention in the treatment of patients with aortic stenosis. Circulation. 2012;125:975-7.

\title{
EDITORIAL COMMENTARY
}

\section{Coronary revascularization in the setting of surgical aortic valve replacement: Do we need extra icing on the cake?}

\author{
Tomas A. Salerno, MD
}

See related article on pages 451-60.

In their retrospective observational study from a single center appearing in this issue of the Journal, Thalji and colleagues ${ }^{1}$ suggest that the performance of coronary artery bypass grafting (CABG) at the time of aortic valve replacement (AVR) is associated with similar operative mortality, albeit with improved overall survival during long- term follow up, to that of patients undergoing AVR without CABG. Although this proposition is at variance with generally accepted medical cognizance and a larger Society of Thoracic Surgeons database study that demonstrated that the addition of CABG to AVR increased surgical morbidity and mortality, it raises the important conjecture that revascularization might have an impact on long-term survival. In

From the Division of Cardiothoracic Surgery and the Department of Surgery, University of Miami Miller School of Medicine and Jackson Memorial Hospital, Miami, Fla.

Disclosures: Author has nothing to disclose with regard to commercial support.

Received for publication Nov 17, 2014; accepted for publication Nov 17, 2014.

Address for reprints: Tomas A. Salerno, MD, 1611 NW 12th Ave, Miami, FL 33136

(E-mail: tsalerno@med.miami.edu).

J Thorac Cardiovasc Surg 2015;149:460-1

$0022-5223 / \$ 36.00$

Copyright $($ c 2015 by The American Association for Thoracic Surgery

http://dx.doi.org/10.1016/j.jtcvs.2014.11.049 this regard, the possibility of operator selection bias in performing or forgoing revascularization at the time of AVR can be ameliorated, but not totally eliminated, by the construction of a propensity score model. Further, the use of the primary outcome of total mortality and the inability to ascertain other cardiac outcomes that could be altered by revascularization, such as the risk of myocardial infarction and cardiac death, opens the door to a multitude of other comorbidities that could have led to a decision not to revascularize and, later and independently, may have affected total mortality.

Considering that it might be impossible to discern the potential for biases in retrospective analyses, and aware of the fact that well-designed prospective studies of revascularization in the setting of AVR are lacking, the clinician is left with the vexing problem of having to apply the knowledge gathered from previous trials in patients undergoing coronary revascularization in a nonvalvular population to a moving field of patients with aortic valvular heart disease that is rapidly shifting into a less-invasive percutaneous approach. This is additionally compounded by the fact that the most recent American Heart Association and American College of Cardiology guidelines ${ }^{2}$ downplay the importance of CABG at time of surgical AVR, and the indication for revascularization for patients with coronary artery lesions greater than $70 \%$ has been downgraded from a class I to a class IIa indication, deemphasizing the importance of $50 \%$ to $70 \%$ stenotic lesions. 
TABLE E1. Reasons for foregoing coronary artery bypass graft (CABG) surgery at time of atrioventricular replacement (AVR): $>70 \%$ coronary artery disease (CAD) and triple-vessel/left main CAD

\begin{tabular}{lcc}
\hline Rationale for nonrevascularization at AVR & $\mathbf{> 7 0} \%$ Stenosis $(\mathbf{n}=\mathbf{1 2 8})$ & High-risk CAD* $(\mathbf{n}=\mathbf{2 0})$ \\
\hline Diagonal/small/distal CAD $\dagger$ & $90(71)$ & $0(0)$ \\
CAD visually insignificant by surgeon $\dagger$ & $26(20)$ & $11(55)$ \\
Nongraftable CAD $\ddagger$ & $8(6)$ & $6(30)$ \\
Prohibitive risk $\S$ & $4(3)$ & $3(15)$ \\
\hline
\end{tabular}

Values are presented as n (\%). AVR, Aortic valve replacement; $C A D$, coronary artery disease. *Eighteen patients with high-risk CAD also had $>70 \%$ coronary stenosis in 1 or more coronary vessels/branches. $\nmid$ These lesions, which surgeons have heretofore considered relatively insignificant, may in fact be a marker of atherosclerotic disease burden and prognostically influential. However, the current data are incapable of proving or refuting this hypothesis. $\ddagger$ As determined by the operating surgeon following review of catheterization films and/or by gross appearance at surgery. In the circumstance whereby concomitant CABG cannot be safely/effectively performed at the time of AVR, these patients may require extra vigilance in follow-up and medical management of CAD. §Two patients were of advanced age, resulting in the surgeon's decision to simplify the surgical procedure (ie, AVR only). Two patients had multiple comorbid conditions precluding the performance of a complex dual surgical procedure. Multivariable Cox models predicting long-term survival adjust for the confounding effects of older age and other well-characterized, prognostically influential risk factors present at AVR (eg, peripheral vascular disease, diabetes, New York Heart Association functional class III-IV, or left ventricular impairment).

TABLE E2. Multivariable predictors of late all-cause mortality: Proximal and nonproximal coronary artery disease (CAD)

\begin{tabular}{|c|c|c|c|c|}
\hline \multirow[b]{2}{*}{ Variable } & \multicolumn{2}{|c|}{ Proximal CAD* $(n=816)$} & \multicolumn{2}{|c|}{ Nonproximal CAD* $(n=492)$} \\
\hline & HR $(95 \%$ CI $)$ & $P$ value & HR $(95 \%$ CI $)$ & $P$ value \\
\hline Peripheral vascular disease & $1.55(1.16-2.05)$ & .004 & $1.97(1.31-2.87)$ & .001 \\
\hline Ejection fraction $<50 \%$ & $1.62(1.27-2.04)$ & $<.001$ & $1.23(0.83-1.77)$ & .30 \\
\hline Diabetes mellitus & $1.59(1.27-1.99)$ & $<.001$ & $1.39(0.99-1.92)$ & .051 \\
\hline NYHA functional class III-IV & $1.71(1.31-2.25)$ & $<.001$ & $1.22(0.87-1.72)$ & .256 \\
\hline Age $\dagger$ & $1.22(1.16-1.28)$ & $<.001$ & $1.40(1.28-1.54)$ & $<.001$ \\
\hline Female sex & $1.38(1.09-1.74)$ & .008 & $0.59(0.77-1.45)$ & .72 \\
\hline Coronary artery bypass graft & $0.58(0.41-0.83)$ & .004 & $0.66(0.49-0.90)$ & .009 \\
\hline
\end{tabular}

$H R$, Hazard ratio; $C I$, confidence interval; $N Y H A$, New York Heart Association; $C A D$, coronary artery disease. *Proximal CAD defined as $\geq 50 \%$ stenosis in the left main artery or the proximal one-third of the left anterior descending, left circumflex, or right anterior descending arteries. All other coronary lesions were considered nonproximal. $\dagger$ Age increase by 5 -year increments.

TABLE E3. Multivariable predictors of late all-cause mortality, by coronary artery disease (CAD) distribution

\begin{tabular}{|c|c|c|c|c|c|c|}
\hline \multirow[b]{2}{*}{ Variable } & \multicolumn{2}{|c|}{ Single-vessel CAD $(n=479)$} & \multicolumn{2}{|c|}{ Double-vessel CAD* $(n=349)$} & \multicolumn{2}{|c|}{ Triple-vessel/left main CAD $*(n=480)$} \\
\hline & HR $(95 \%$ CI $)$ & $P$ value & HR $(95 \%$ CI $)$ & $P$ value & HR $(95 \%$ CI $)$ & $P$ value \\
\hline Peripheral vascular disease & $1.50(0.96-2.25)$ & .072 & $1.68(1.06-2.58)$ & .03 & $1.86(1.29-2.63)$ & .001 \\
\hline Ejection fraction $<50 \%$ & $1.52(1.02-2.20)$ & .04 & $1.31(0.89-1.91)$ & .17 & $1.61(1.19-2.16)$ & .002 \\
\hline Diabetes mellitus & $1.40(0.99-1.95)$ & .051 & $1.71(1.19-2.42)$ & .004 & $1.47(1.10-2.95)$ & .01 \\
\hline NYHA functional class III-IV & $1.44(1.03-2.04)$ & .03 & $1.53(1.03-2.04)$ & .03 & $1.35(0.94-1.97)$ & .11 \\
\hline Age $\dagger$ & $1.34(1.22-1.47)$ & $<.001$ & $1.40(1.28-1.61)$ & $<.001$ & $1.16(1.05-1.22)$ & .004 \\
\hline Female sex & $1.06(0.76-1.47)$ & .73 & $1.06(0.73-1.51)$ & .75 & $1.52(1.11-2.05)$ & .009 \\
\hline Coronary artery bypass grafting & $0.63(0.46-0.86)$ & .004 & $0.63(0.41-1.01)$ & .058 & $0.73(0.40-1.50)$ & .36 \\
\hline
\end{tabular}

$H R$, Hazard ratio; $C I$, confidence interval; NYHA, New York Heart Association; $C A D$, coronary artery disease. *Considering that only 59 patients with double-vessel CAD and 20 with triple-vessel/left main CAD underwent isolated AVR in our population, it is likely that our study was underpowered to detect a survival impact of coronary artery bypass grafting at atrioventricular replacement. $\dagger$ Age increase by 5 -year increments. 
TABLE E4. Multivariable predictors of late all-cause mortality in single-vessel left anterior descending (LAD) artery disease*

\begin{tabular}{lcc}
\hline \multirow{2}{*}{ Variable } & \multicolumn{2}{c}{ Single-vessel LAD disease $(\mathbf{n}=\mathbf{2 6 5})$} \\
\cline { 2 - 3 } & HR $(\mathbf{9 5} \% \mathbf{C I})$ & $\boldsymbol{P}$ value \\
\hline Peripheral vascular disease & $1.63(0.88-2.84)$ & .11 \\
Ejection fraction $<50 \%$ & $1.36(0.77-2.30)$ & .28 \\
Diabetes mellitus & $1.33(0.86-2.02)$ & .19 \\
NYHA functional class III-IV & $1.27(0.81-2.06)$ & .31 \\
Age $\dagger$ & $1.47(1.28-1.69)$ & $<.001$ \\
Female sex & $1.33(0.86-2.05)$ & .20 \\
CABG & $0.48(0.31-0.74)$ & $<.001$ \\
\hline
\end{tabular}

$H R$, Hazard ratio; $C I$, confidence interval; NYHA, New York Heart Association; $C A B G$, coronary artery bypass grafting; $L A D$, left anterior descending artery. *Due to the small number of events (ie, late deaths) in patients with single-vessel left circumflex artery disease and single-vessel right coronary artery disease, construction of predictive models with $>2$ variables in these patient subgroups would have resulted in overfitting and hence was inappropriate. $\dagger$ Age increase by 5 -year increments. 